\title{
Social implications of alcohol consumption
}

\author{
By J. C. McKenzie, Food $\Xi^{\circ}$ Drink Research Limited, Centre House, \\ I 4-I I6 Charing Cross Road, London $\mathrm{WC2H}$ of $\mathrm{R}$
}

\section{Introduction}

To a large extent the papers at today's meeting are concerned with physical abnormalities occurring as the result of alcohol consumption. As such my paper is something of 'an odd man out' in two ways. Firstly, I am concerned to examine the social and psychological reasons behind the consumption of alcohol. And secondly, I am concerned as much, if not more, with the normal unharmful effects resulting from this consumption.

In a way much of my paper is concerned with establishing some sense of perspective about alcohol consumption for, however well known the facts are, the subject remains emotionally highly charged. Perhaps just one example will sufficefrom a recent publication of the National Society for the Prevention of Cruelty to Children (Stewart, I971).

About one person in five hundred in England and Wales is an acute alcoholic, that is to say an addict.
Two or three times as many are chronic drinkers, dependent on alcohol to maintain their personal
and social equilibrium. The National Council on Alcoholism has calculated that the cost to the
nation, in terms of prison and social security maintenance, sickness and hospital treatment,
absentecism, etc. is upward of $\$ 40$ million. Alcohol is responsible to a greater or lesser extent for
the killing or maiming of thousands of people on the roads and plays some part in much of the crime
committed in this country.

Yet millions of pounds every year are spent in advertising drink and about 350 ooo people in this country work at its manufacture and distribution.

Alcohol is 'socially acceptable'.

This is by no means an accurate and complete picture of the situation as I shall attempt to show in this paper. Firstly I shall give some details about consumption of alcohol and diseases associated with it, and then go on to show the role alcohol plays in contemporary society. I shall end by examining the social causes and consequences of alcoholism.

\section{Some facts about alcohol consumption in Great Britain}

Consumer expenditure on alcoholic drink in the United Kingdom during 1970 was $f_{2}$ I 78000000 of which nearly half $(43 \%)$ went straight back to the Government in tax (Fig. I). In terms more real to us the average person spent $\$ 39$ per annum on alcoholic drink-this is some $7 \%$ of their total expenditure. Given that a proportion of this population is below the age likely to find drink acceptable and that a small percentage of adults are total abstainers, the figure for 'drinkers' becomes 
nearly $£^{80}$ per annum. There are nearly 140000 licensed outlets for the sale of alcohol - some 105000 being on licensed premises and 35000 off-licences.

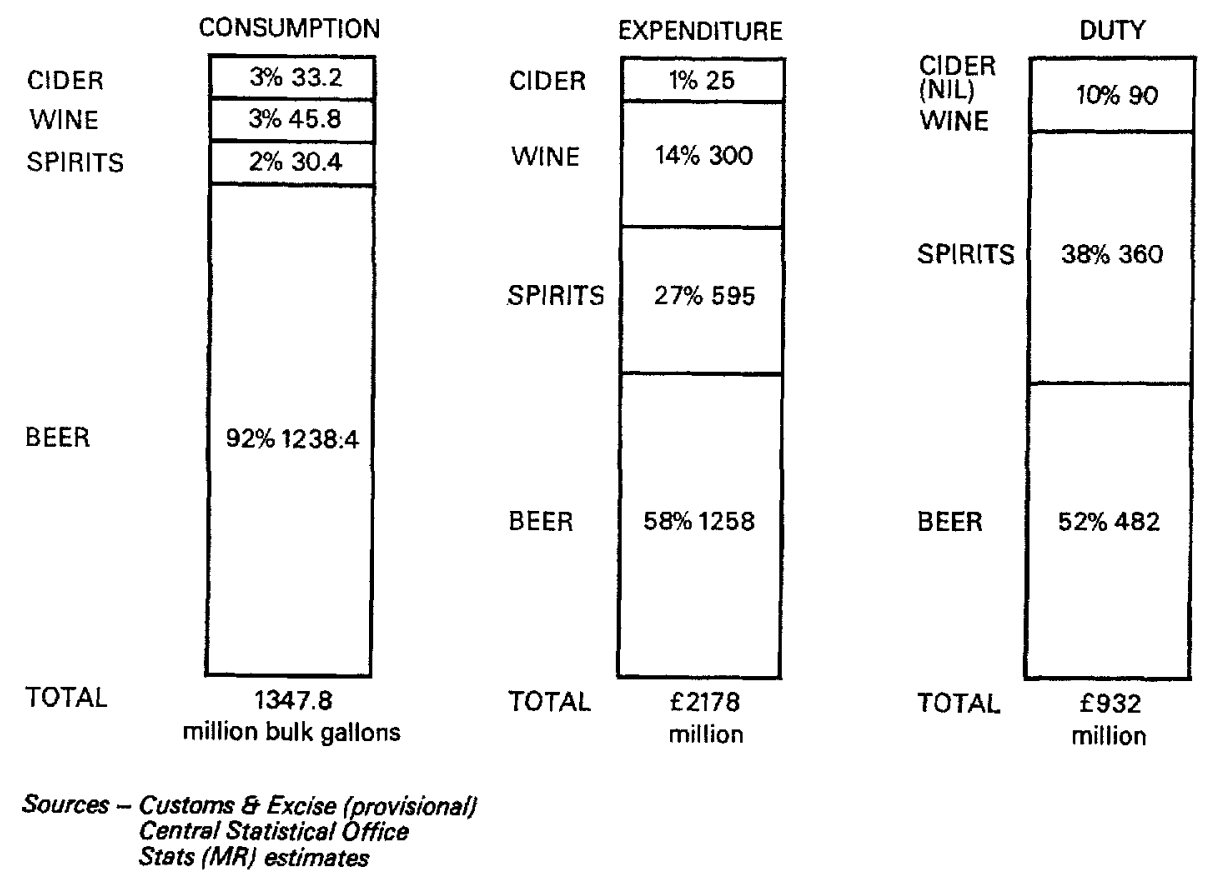

Fig. I. Consumption of various types of drink, the amount spent and the duty paid on them in 1970 (I gallon (imperial) $=4.5461$ ). (Nutt, 1971 : with acknowledgement to The Grocer.)

Perhaps most significantly, in view of what has been said earlier about diseases resulting from alcohol consumption, $92 \%$ of alcoholic drinks consumed in this country is beer-a drink with such a low content of alcohol per fluid ounce that other than causing an occasional hangover its impact on 'disease' is likely to be negligible. In terms of expenditure and customs duty the predominance, although reduced, of beer remains (Nutt, 1971).

Trends in consumption are emerging both between and within the various alcoholic drink categories. Thus consumption of wines and, to a less degree, spirits is increasing faster than that of beer (Fig. 2). Within the spirits category, consumption of brandy and whisky is increasing rapidly while that of gin is declining at some speed (Fig. 3). Consumption of draught lager and keg beer is growing fast while that of mild and brown ale is declining.

\section{The social advantages of drinking}

Since time immemorial consumption of alcohol has been an everyday occurrence. Not surprisingly therefore the World Health Organization in defining alcoholism openly recognizes that alcohol consumption forms a part of our everyday life styles. Alcoholism is 'any form of drinking which in its extent goes beyond traditional 


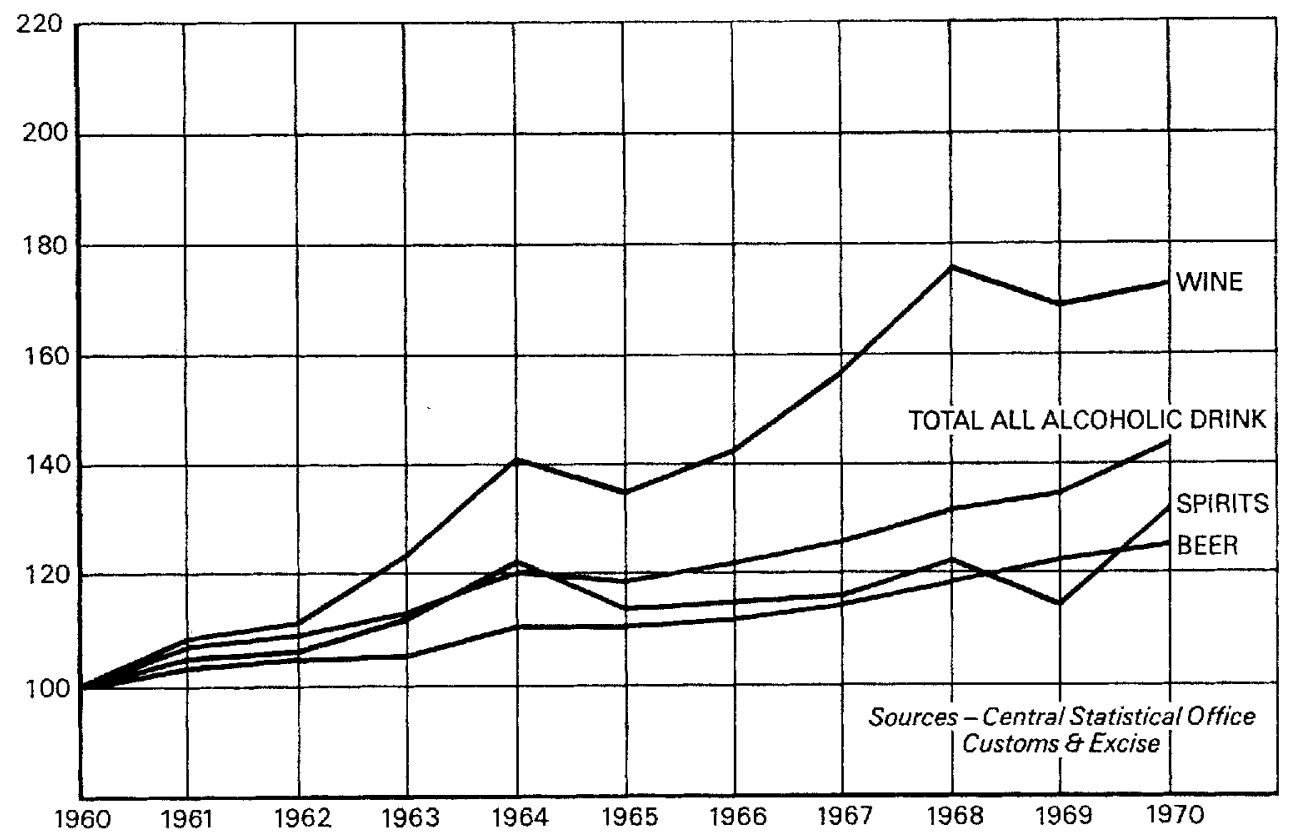

Fig. 2. Indices of consumption of various types of alcoholic drink during the period 1960-70. (Nutt, I971: with acknowledgement to The Grocer.)

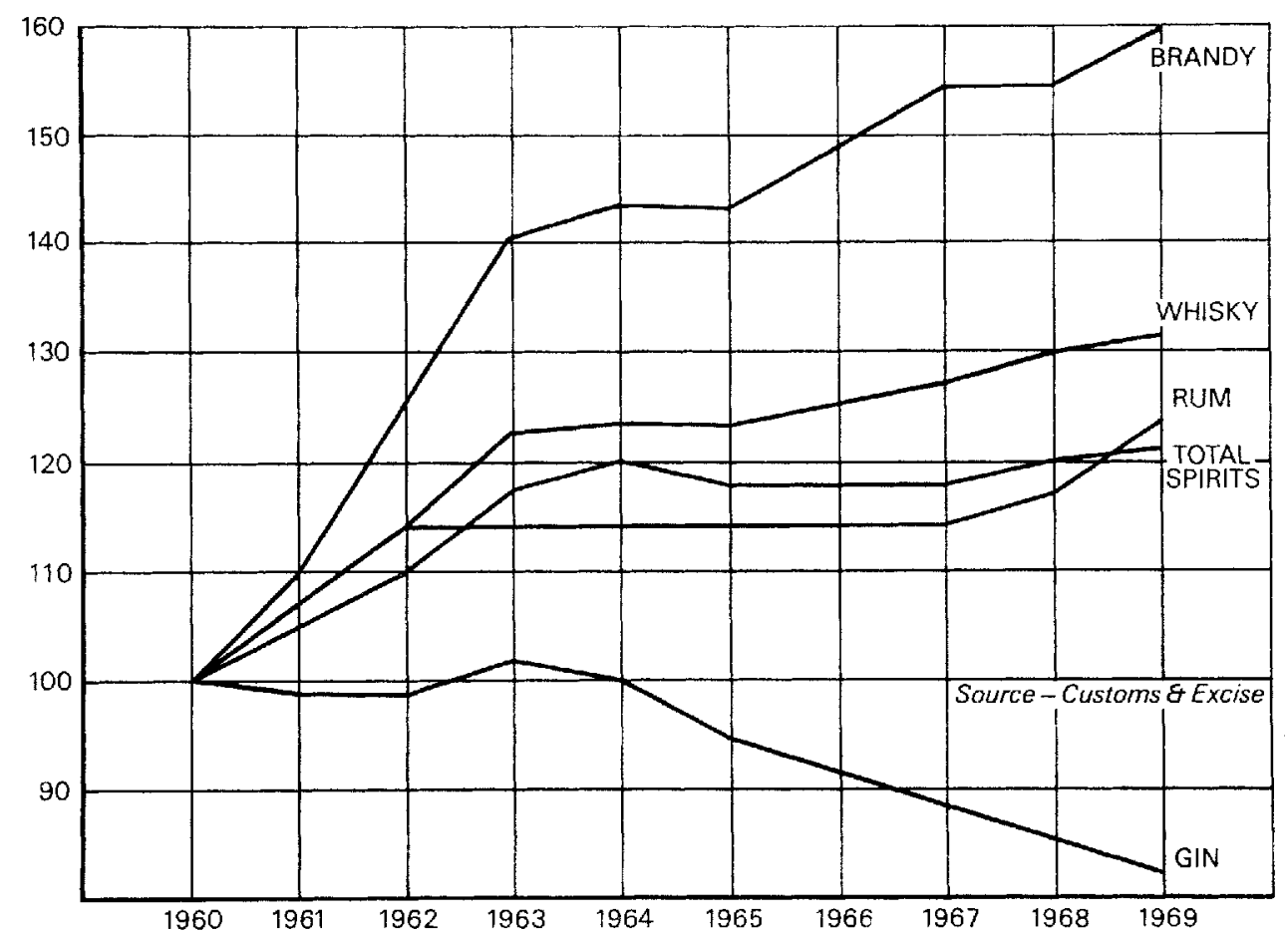

Fig. 3. Indices of the volumes of different spirits consumed (3-year moving averages). (Nutt, I97 I : with acknowledgement to The Grocer.) 
and customary dietary use, or the ordinary compliance with the social drinking customs of the whole community concerned'. [Author's italics.] (World Health Organization, 1952).

In fact, alcohol contributes a great deal to our contemporary society in a number of ways. Firstly we use it as a symbol of affluence or celebration-a champagne reception, a cocktail party, a 'booze-up', a bottle party, to name but a few drinking occasions, which all convey images to every one of us and portray situations over and above the actual drinking context. Yet without the drink the situation would lose tremendously. Thus in such circumstances alcohol helps to make an occasion.

Secondly, it removes inhibitions. Mostly this is in a small way and is a highly desirable means to ease tension. You walk into a room full of strangers and a glass of sherry and a cigarette break the ice. Equally it often overcomes any pretentious outward facade or play-acting role - we become more ourselves - 'the real us'. It also encourages congeniality. Of course in more extreme situations drink can lead us to overcome desirable inhibitions (or at least those society currently deems as desirable) and can cause harm.

Thirdly, for young men, in particular, the 'pub' situation is a major aspect of their life style - the whole complex of the place, the atmosphere, the beer, the company, is wholly amenable to them and represents very much the male 'pack' situation equivalent to 'coffee parties' for women.

Lastly, drink has been traditionally used as a means to ease personal stress, to forget and to cause oblivion. This may not always be a bad thing. The funeral feast was a traditional means by which poor societies reconciled themselves to the death of a loved one. The man who takes a stiff whisky at the end of the day uses it to help him relax. A large drink to overcome a scare, a shock or a disaster is psychologically justifiable. Clearly, particularly behind the 'oblivion' category, more dangers exist-indeed as is shown later in this paper it may well be a classic sign of alcoholism. Nevertheless, in general terms drink may contribute a good deal to the smooth running of the individual's life and the corporate functioning of society.

\section{Extent of alcoholism}

Against a background of increasing consumption of alcohol we find a general picture of declining deaths from alcoholism, although the trend has been reversed in the last Io years among men. Similarly, deaths from cirrhosis of the liver have declined (Office of Health Economics, I970) (Figs 4 and 5).

The exact incidence of alcoholism in a given population is never easy to establish but Table I shows figures taken from two authoritative accounts for England and Wales of 1100 and 865 per 100000 population. Both sources give an indication of the favourable position in this country compared to much of Europe and North America. Perhaps because of this relatively favourable position the disease is not viewed as serious by the British public. Thus, a recent survey showed alcoholism to be placed below cancer, heart disease, drug addiction and tuberculosis (Allied Breweries Ltd, personal communication) (Table 2). 


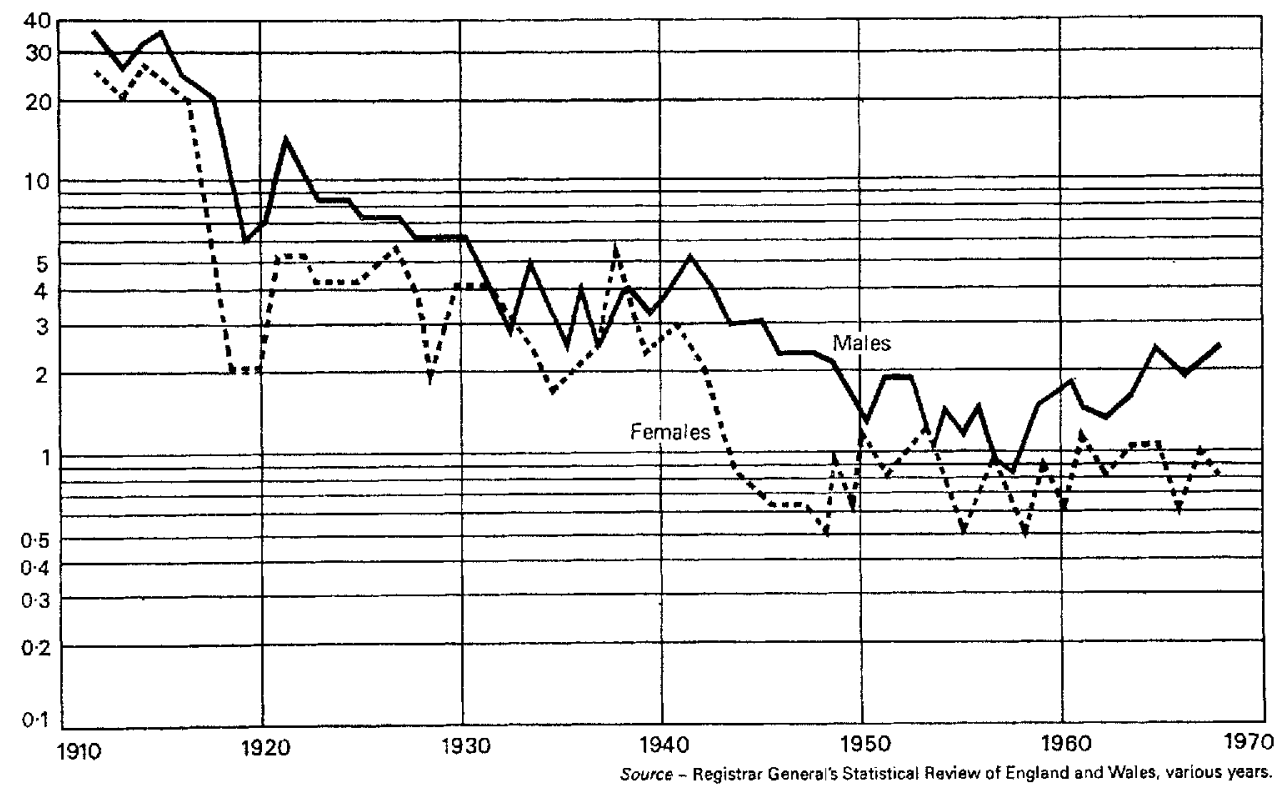

Fig. 4. Death-rates (per million living) from alcoholism for males and females in England and Wales, I911-67. (From Office of Health Economics, I970; with acknowledgement to that Office.)

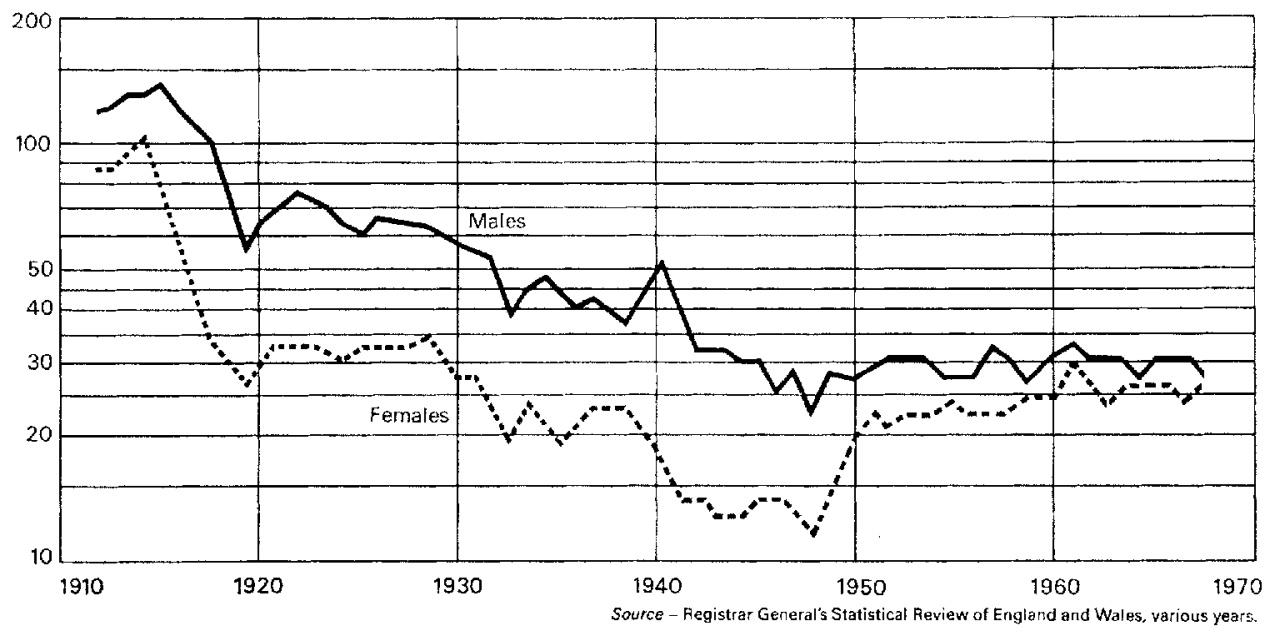

Fig. 5. Death-rates (per million living) from cirrhosis of the liver for males and females in England and Wales, r9x $1-67$. (From Office of Health Economics, x 970: with acknowledgement to that Office.) 
Table I. Prevalence of alcoholism (rates per 100000 population aged 20 years or more) in selected countries (Source: Office of Health Economics, 1970)

\begin{tabular}{llcc} 
Place & \multicolumn{1}{c}{ Year } & Jellinek* method & $\begin{array}{c}\text { Office of Health } \\
\text { Economicst }\end{array}$ \\
France & $195 \mathrm{I}$ & 5200 & 7300 \\
USA & 1953 & 4390 & - \\
Chile & 1950,1953 & 3610 & 450 \\
Canada (Ontario) & 1961 & 2460 & 2375 \\
Switzerland & 1953,1947 & 2100 & 2700 \\
Denmark & 1948 & 1950 & $175 \circ$ \\
Finland & $1951-7$ & 1120 & $133 \circ$ \\
England and Wales & $1948,1960-3$ & 1100 & 865
\end{tabular}

"The Jellinek formula is $\mathrm{A}=\mathrm{PD} \div \mathrm{K}$. $\mathrm{A}$ is the total number of alcoholics in a given year, $\mathrm{D}$ the number of cirrhosis deaths, $\mathrm{P}$ the proportion of these attributable to alcoholism and $\mathrm{K}$ the percentage of all alcoholics with complications who die of cirrhosis of the liver. These measures can be obtained from hospital records and autopsy surveys. $\mathrm{R}$, the ratio of all alcoholics to those with complications, was added to the numerator later (World Health Organization, 195 I).

†Based on field surveys (either interviewing reliable informants or by sampling the general population).

It is generally accepted that alcoholism affects more men than women; it has been suggested that the proportion is between four and seven times as many men as women. There is also a pronounced peak in incidence between 40 and 50 years of age (Office of Health Economics, 1970).

Table 2. Results of a survey asking the question: 'What are the three most serious problems facing people in Britain today?' as given by different sections of the population

\begin{tabular}{|c|c|c|c|c|c|c|}
\hline \multirow[b]{2}{*}{ Disease } & \multirow[b]{2}{*}{$\begin{array}{c}\text { Total } \\
\%\end{array}$} & \multicolumn{2}{|c|}{ Social class } & \multicolumn{3}{|c|}{ Region } \\
\hline & & $\begin{array}{c}\mathrm{ABCl}^{*} \\
\%\end{array}$ & $\begin{array}{c}\mathrm{C}_{2} \mathrm{DE} \\
\% \\
\%\end{array}$ & $\begin{array}{l}\text { North } \\
\%\end{array}$ & $\underset{\%}{\text { Midlands }}$ & $\begin{array}{c}\text { South } \\
\%\end{array}$ \\
\hline Cancer & $8_{3}$ & 85 & 82 & 79 & 86 & 86 \\
\hline Heart trouble & 73 & 82 & 68 & 72 & $7^{6}$ & 72 \\
\hline Drug addiction & 47 & 40 & 51 & 45 & 49 & 49 \\
\hline Arthritis & 36 & 44 & 32 & 29 & 40 & 41 \\
\hline Alcoholism & $2 x$ & I 8 & 23 & 27 & 18 & 18 \\
\hline Asthma & $\mathrm{I}_{3}$ & I3 & 14 & 15 & I3 & 12 \\
\hline Tuberculosis & I3 & 8 & 15 & 17 & 8 & 12 \\
\hline Diabetes & I 2 & 10 & 13 & 16 & 9 & I I \\
\hline No. of people & & & & & & \\
\hline interviewed & 460 & 165 & 295 & 165 & I 43 & 152 \\
\hline
\end{tabular}

*The social class terms $\mathrm{ABC}$ a and $\mathrm{C}_{2} \mathrm{DE}$ are agreed ratings provided by the Market Research Society in the $\mathrm{UK} . \mathrm{ABC}_{\mathrm{I}}$ approximates to the professional and white-collar workers, and $\mathrm{C}_{2} \mathrm{DE}$ to semi-skilled and manual workers, old age pensioners and the unemployed.

\section{The social and psychological problems of alcoholism}

For the great majority of the population we have shown that alcoholic drinks are not only pleasurable in taste terms but also have a major role to play in our life styles. But for a minority they are a vehicle to personal disaster. 
The development of alcoholism, perhaps more dramatically than any other illness, is reflected in changes in the individual's social behaviour regardless of his physical condition. This is described dramatically by Kessel \& Walton (1967). They suggest three stages in the development of alcoholism: excessive drinking, the addictive stage and chronic alcoholism. Excessive drinkers are not alcoholics though they may become so. In the early stages, the excessive drinker drinks in the same pattern as social drinkers but drinks more, starts to spend more time drinking and begins to do so surreptitiously. He adopts strategies to obtain more drink without others knowing. Drinking affords him positive relief from specific problems and lessens tension. He begins to use it to relieve all his problems and soon develops increased tolerance, where he has to drink more to obtain the same relief; he often has increased guilt feelings.

This phase moves on to the period where alcohol is a necessity and the drinker is now dependent on alcohol. He often drinks to the point of drunkenness, he suffers loss of memory and is unable to regulate his drinking. As soon as a small amount of alcohol is consumed the demand for alcohol continues until either the alcohol runs out or the drinker is too sick or intoxicated to drink more. His interests become narrower and drink is the main concern of his life. His work-record deteriorates and he drinks heavily during the working day. Psychologically he is beset by remorse and dwells on past achievements. Debts mount up, social isolation occurs and, if married, relations deteriorate with his wife and family-he often becomes morbidly jealous. At this point he may begin to be continuously drunk throughout the weekend and may lose his job. He begins to drink in the morning, conceals supplies of liquors, neglects his food and may make suicide attempts.

Clearly our main concern must be with the factors that turn someone from a 'social drinker' to an alcoholic and I would suggest that there are strong grounds to suggest that addictive consumption of alcohol is the effect of basic psychological deficiencies in an individual. Robins, Bates \& $\mathrm{O}^{\prime} \mathrm{Neal}(\mathrm{1} 962)$ did a 30 -year followup study on 500 children who had been seen in a child guidance clinic and a group of matched controls. They found a higher proportion of the children from the clinic developed alcoholism than among the controls.

Some psychoanalysts favour another thesis. They suggest that alcoholism is associated with an unusual experience at the oral stage of development, the stage when the infant is completely dependent on the mother's nurture. Later experiences call for the fulfilment of conflicting needs, of independence and achievement and thus the repression of dependency wishes. Alcohol is a device for coping with these problems by, some say, symbolically re-creating a satisfying dependency.

There is also evidence to suggest that emotional stress resulting from changes in marital status may be of significance (Table 3). While in terms of divorce it is difficult to ascertain whether alcoholism is the cause or effect, this is undoubtedly not so where the spouse has died. Again, as was indicated earlier, alcoholism is particularly prevalent amongst middle-aged men-that is those suffering from the pressures of stress jobs or those who have to reconcile themselves to the fact they have not 'made it'. 
Table 3. Incidence of alcoholism in 1967 according to marital status (rates per 100000 of population) (Source: Office of Health Economics, 1970)

\begin{tabular}{|c|c|}
\hline Status & UK \\
\hline Widowed & 1360 \\
\hline $\begin{array}{l}\text { Divorced } \\
\text { Single }\end{array}$ & 680 \\
\hline Married & $55^{\circ}$ \\
\hline
\end{tabular}

The significance of these issues is important in determining our attitude to alcohol consumption. If alcoholism is an 'effect' rather than a cause, then in medical terms undoubtedly our attention must be directed towards dealing with the root cause of the problem rather than with the symptom. Certainly much of the evidence I have put forward would lead me to suggest this should be concerned with mental rather than physical health and well-being.

In any event considerably greater research is required to determine what makes an individual move from 'normal' drinking to addiction and how the 'risk' factor may be diminished. If this greater understanding can be achieved, then alcohol may well prove to be one of the few great companions and solaces of our time that does not bring with it to the community considerable health hazards.

\section{REFERENCES}

Kessel, N. \& Walton, H. J. (I 966). Alcoholism. New York, NY: Humanities Press.

Nutt, C. J. (I971). The Grocer 13 November, I971, pp. 58,61 and 77.

Office of Health Economics (1970). Alcohol Abuse. London: Office of Health Economics.

Robins, L. N., Bates, W. \& O'Neal, P. ( 1962 ). In Society, Culture and Drinking Patterns [D. J. Pitman and C. R. Snyder, editors]. New York: John Wiley \& Sons Inc.

Stewart, W. F. R. (1971). Drink, Drugs and the Family. London: National Society for the Prevention of Cruelty to Children.

World Health Organization (1951). Tech. Rep. Ser. Wld Hlth Org. no. 42.

World Health Organization (1952). Tech. Rep. Ser. Wld Hlth Org. no. $4^{8 .}$ 